\title{
Pre-clinical evaluation of ceramic femoral head resurfacing prostheses using computational models and mechanical testing
}

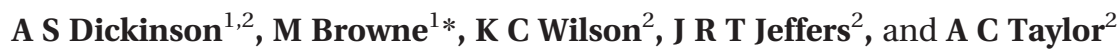 \\ ${ }^{1}$ Bioengineering Science Research Group, University of Southampton, Southampton, UK \\ ${ }^{2}$ Finsbury Development Ltd, Leatherhead, Surrey, UK \\ The manuscript was received on 25 January 2011 and was accepted after revision for publication on 4 May 2011.
}

DOI: $\quad 10.1177 / 0954411911411605$

\begin{abstract}
Ceramic-on-ceramic hip resurfacing can potentially offer the bone-conserving advantages of resurfacing while eliminating metal ion release. Thin-walled ceramic resurfacing heads are conceivable following developments in the strength and reliability of ceramic materials, but verification of new designs is required. The present study aimed to develop a mechanical pre-clinical analysis verification process for ceramic resurfacing heads, using the DeltaSurf prosthesis design as a case study.

Finite element analysis of a range of in vivo scenarios was used to design a series of physiologically representative mechanical tests, which were conducted to verify the strength of the prosthesis. Tests were designed to simulate ideal and worst-case in vivo loading and support, or to allow comparison with a clinically successful metallic device.

In tests simulating ideal loading and support, the prosthesis sustained a minimum load of $39 \mathrm{kN}$ before fracture, and survived 10000000 fatigue cycles of $0.534 \mathrm{kN}$ to $5.34 \mathrm{kN}$. In worstcase tests representing a complete lack of superior femoral head bone support or pure cantilever loading of the prosthesis stem, the design demonstrated strength comparable to that of the equivalent metal device.

The developed mechanical verification test programme represents an improvement in the state of the art where international test standards refer largely to total hip replacement prostheses. The case study's novel prosthesis design performed with considerable safety margins compared with extreme in vivo loads, providing evidence that the proposed ceramic resurfacing heads should have sufficient strength to perform safely in vivo. Similar verification tests should be designed and conducted for novel ceramic prosthesis designs in the future, leading the way to clinical evaluation.
\end{abstract}

Keywords: ceramic hip resurfacing, pre-clinical analysis, mechanical testing, FE analysis

\section{INTRODUCTION}

Hip resurfacing was developed as a bone-conserving alternative to total hip replacement (THR), with the additional benefit of more inherent joint stability due to the large-diameter bearing $[\mathbf{1}, 2]$. For the target, young male patient, the Australian

*Corresponding author: Bioengineering Science Research Group, 5/3019, University of Southampton, Southampton, SO17 1BJ, UK.

email:doctor@soton.ac.uk
Orthopaedic Association National Joint Replacement Registry [3] reports slightly lower revision rates for hip resurfacing compared with THR (2.2 per cent revised at 5 years versus 2.5 per cent for THR, and 2.4 percent revised at 7 years versus 2.8 per cent for THR), indicating that hip resurfacing is a suitable treatment for certain high-demand patients. The main causes of failure in resurfacing hip replacement (RHR) have been reported as early femoral neck fracture, infection, and loosening of the femoral prosthesis [4]. In recent studies, another failure mechanism has been identified, linked to 
ions released by the cobalt-chromium $(\mathrm{CoCr})$ metal bearing resulting in fluid-filled bursae, sometimes linked with metallosis and tissue staining upon revision $[\mathbf{5}, \mathbf{6}]$.

Ceramic bearing materials have over four decades of successful use in THR [7], with the principal advantages over metals of higher wear resistance and biocompatibility. Alumina ceramic has been used for femoral head resurfacing prostheses in hemiarthroplasty [8] and in total resurfacing articulating against polyethylene (PE) [9-11] or ceramic cups [12]. Ceramic-PE resurfacings had high failure rates due to osteolysis caused by PE debris, similar to the experience with metal-on-PE resurfacings $[13,14]$. A design with a monolithic press-fit ceramic cup $[12,15]$ had a high incidence of radiographic loosening, in the absence of a rough bioactive coating or cement for fixation. Adequate fixation was achieved instead through three large pegs, but these features come at the expense of bone conservation.

The clinical history, therefore, indicates that the main limitations of a ceramic resurfacing head were related to the early-generation PE acetabular counter-bearing material and the fixation, rather than to the ceramic itself. In metal-on-metal resurfacing, limitations of fixation have largely been overcome by a cement-fixed femoral component, as demonstrated by the improved performance of these devices reported in the registers [3] and by followup studies $[4, \mathbf{1 6}, \mathbf{1 7}]$. Limitations of the acetabular bearing surface may also be overcome with a ceramic resurfacing head, as ceramic-on-metal THR bearings have shown promise in early clinical results [18]. A design goal is to remove $\mathrm{CoCr}$ entirely, using a ceramic-ceramic resurfacing bearing couple that could display the excellent clinical performance achieved by ceramic-on-ceramic bearings in THR [19].

Prior to clinical use, the strength of any new prosthesis system must be verified. For a ceramic resurfacing prosthesis, in particular, the strength of the ceramic structure, its fixation, and load transfer to the underlying bone must be verified. Thorough mechanical pre-clinical analysis testing standards are in place for THR implants, but there is an absence of established standard testing methods for resurfacings. Little information is available on in vitro tests for hip resurfacing designs, limited to brief details of mechanical verification tests of the Birmingham Hip Resurfacing (BHR) prosthesis (Smith \& Nephew, Memphis, Tennessee, USA) made available by the US Food and Drug Administration's Center for Devices and Radiological Health (CDRH) [20]. The purpose of the present study was the development of a mechanical strength verification process for pre-clinical analysis of ceramic resurfacing head prostheses.

\section{METHODS}

\subsection{Ceramic-on-ceramic hip resurfacing design}

The following is a summary of the development of a computational and mechanical testing programme to assess the structural validity of novel ceramic resurfacing head prosthesis designs. For all tests and analyses, the design used as a case study was the DeltaSurf $^{\circledR}$ ceramic femoral resurfacing head (Finsbury Development Ltd, Leatherhead, UK; CEMarked 05/2010). This prosthesis design evolved from a benchmark clinically successful metal-onmetal resurfacing device (the ADEPT $^{\circledR}$ Hip Resurfacing; Finsbury Orthopaedics Ltd) (Fig. 1, [3]). The DeltaSurf prosthesis is manufactured from a zirconia-toughened alumina composite, BIOLOX Delta (CeramTec AG, Plochingen, Germany [21]), the most commonly used toughened structural bioceramic. It is designed for use with either a monolithic CoCr cup or a large-bore ceramic cup. The benchmark ADEPT prosthesis' bearing shape, wall thickness, and basic internal geometry of a chamfered, tapered cylinder were retained, owing to their proven bearing performance and sufficient primary implant stability with bone cement [3]. The ceramic resurfacing head, however, features two main design changes to avoid generating excessive tensile stress in the ceramic structure. First, the cement pockets within the head in which bone cement cures, aiding torsional stability, were replaced with less stressconcentrating, smoother, circular-section scallops. Second, the metaphyseal stem was shortened so that it terminates at the spherical centre of the bearing surface. The long stem in traditional designs is intended to act primarily as a surgical alignment aid [2], although its load bearing is thought to contribute to femoral component loosening failures, possibly through proximal stress shielding [22-24]. Therefore, a second perceived biomechanical advantage to the short stem was to reduce the risk of prosthesis loosening compared with traditional designs as a result of proximal femoral head and neck strain shielding, arising from undesirable load bearing of the stem [25]. The short stem would instead intentionally load the bone's natural strain path - the dense principal trabecular band in the femoral head - theoretically altering the bone strain distribution less and generating a smaller remodelling stimulus. 


\subsection{Finite element analysis (FEA) for implanted prosthesis stress distribution}

The resurfacing head prosthesis' in vivo finite element (FE) modelling approach has been reported previously [24], thus only a summary is included here. A computed tomography (CT) scan of the left femur of a 63-year-old male patient with no known orthopaedic disease was obtained, and an FE mesh with CT-based materials was generated using a combination of the following softwares: Amira (Mercury Computer Systems Inc., Chelmsford, Massachusetts, USA), SolidWorks 2007 (SolidWorks Corp., Concord, Massachusetts, USA), ANSYS 12 (ANSYS Inc., Canonsburg, Pennsylvania, USA), and Bonemat (Rizzoli Institute, Bologna, Italy). The femoral head was resurfaced with the ceramic prosthesis design (material, BIOLOX Delta; modulus of elasticity $E$, Poisson's ratio $\nu$, and flexural strength $\sigma_{\text {flex }}$ of $350 \mathrm{GPa}, 0.22$, and $1150 \mathrm{MPa}$, respectively [21]). The implant was fixed with an approximately uniform layer of polymethylmethacrylate (PMMA) bone cement $(E=2.8 \mathrm{GPa}[\mathbf{2 6}])$ : a $3 \mathrm{~mm}$ thick layer of cement penetrated bone and cement mantle [27] was defined at the implant-bone interface. The model was subjected to an $8 \mathrm{kN}$ load representing an extreme eight to nine times body weight stumbling joint contact force [28] and an obese assumed body mass, applied through a ceramic acetabular cup. The geometry of the modelled prosthesis was simplified slightly compared with that of the implant (Fig. 1), so that the cement pocket was axisymmetric, running around the entire circumference of the prosthesis. This allowed the head to be map-meshed with second-order hexahedral finite elements giving high results accuracy and represents a worse case compared with the actual implant, as the modelled implant had a wall thickness less than or equal to the proposed design. The effect of prosthesis positioning was investigated by implanting the prosthesis in three orientations: with the prosthesis stem aligned with the femoral neck axis and with $10^{\circ}$ of varus and valgus inclination. The prosthesis strength was assessed by calculating the ratio of the maximum (tensile) principal stress to the flexural strength of the ceramic (1150 MPa [21]).

\subsection{Experimental tests}

Mechanical tests were designed based on results obtained from the FEA. The main departure from the traditional design was the use of the ceramic material, so its strength was the main focus of the test programme. The predicted stress concentrations from the FE results were noted and a test designed to re-create each of the main stress concentrations. As the other main departure from the baseline design, the strength of the prosthesiscement interface required verification, so an additional torsion strength test was designed. Key features of these tests are summarized in Table 1 and are described in detail in the sections that follow.

\subsubsection{Stem strength test}

Stem fracture in bending was investigated by fixing rigidly the bearing shell in a stainless steel box fixture and exerting a cantilever load at the stem tip (Fig. 2). This test was performed in fatigue using a servohydraulic axial testing machine (Instron 8874; Instron Corp., Norwood, Massachusetts, USA), with the following conditions: peak load $=636 \mathrm{~N}$ [20],

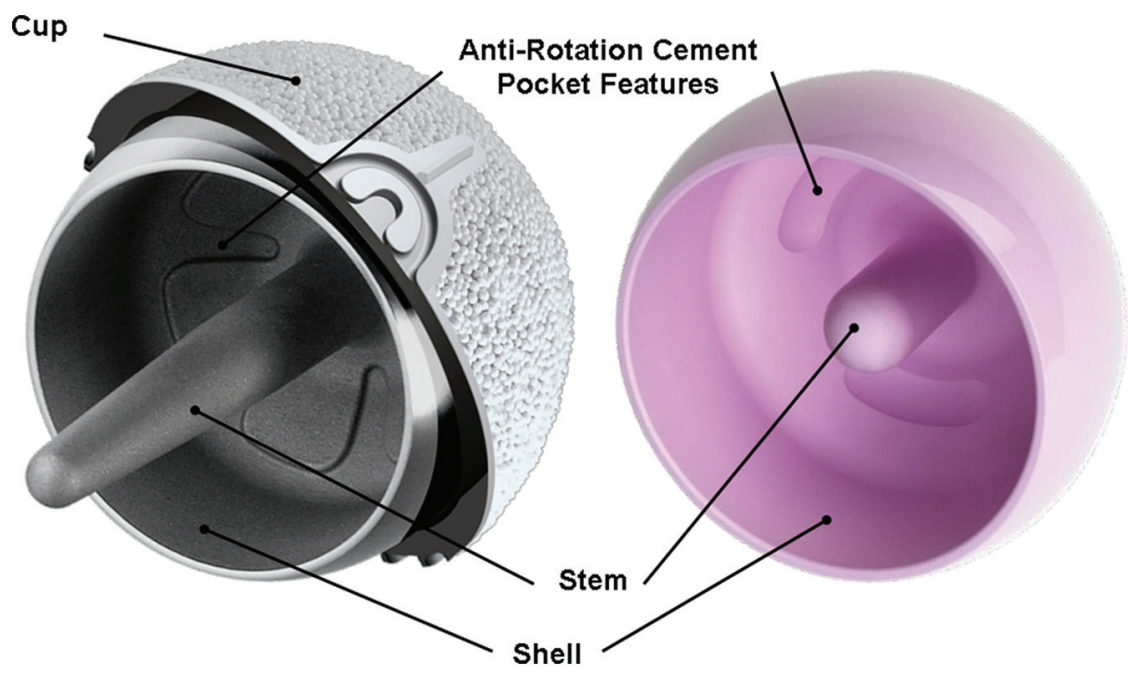

Fig. 1 Photograph of the ADEPT metal-on-metal hip resurfacing prosthesis (left) and the DeltaSurf ceramic resurfacing head prosthesis (right) 
Table 1 Summary of prosthesis stress concentrations, and mechanical tests for each

\begin{tabular}{ll}
\hline Prosthesis stress concentrations, based on FEA predictions & Verified by test \\
\hline 1 Stem root tensile stress in normal loading & Stem strength test \\
2 Internal surface tensile stress, under bearing contact patch in normal loading & Implanted head strength test \\
3 Internal surface tensile stress, near shell rim in normal loading with varus orientation & Unsupported head strength test (intact heads) \\
4 Shell rim tensile stress, in impaction loading & Unsupported head strength test (impacted heads) \\
5 Prosthesis-cement interface shear stress, under frictional torque loading & Prosthesis-cement fixation strength test \\
\hline
\end{tabular}

$R$ ratio $=0.1$, frequency $=10 \mathrm{~Hz}$, run to 5 million cycles. The load cell capacity was $25 \mathrm{kN}$. Two prosthesis sizes were tested, with $40 \mathrm{~mm}$ and $58 \mathrm{~mm}$ bearing diameters (hereafter referred to as 'size 40' and 'size 58' heads), representing the smallest and largest of the size range and expected to capture the worst case. Three prostheses of each size were tested. The test was repeated with three more implants under static conditions with ramp loading at a crosshead displacement rate of $0.05 \mathrm{~mm} / \mathrm{s}$, until fracture of the stem when the applied load was recorded.

\subsubsection{Implanted head strength test}

For a correctly oriented prosthesis, the main FEA-predicted stress concentration is located inside the head, below the bearing contact patch. The head strength under this stress concentration was tested by cementing the head onto a polyphenylsulfone stub $(E=2.34$ GPa [29]) representing a femoral head and neck, and loaded through a metal acetabular cup at $45^{\circ}$ to the neck axis (Fig. 3). This prosthesis orientation was selected to simulate a worst case, where a cement pocket was aligned under the loading patch, so that the thinnest wall region was tested. The polyphenylsulfone femoral head analogue had an internal steel core to provide strength and allow testing to the failure of the prosthesis rather than the support structure. Two tests were performed in this configuration. First, a fatigue test was conducted using a servohydraulic axial testing machine (Dartec 9601; Dartec Ltd, Stourbridge, UK) under the following conditions: peak load $=5.34 \mathrm{kN}[30], R$ ratio $=0.1$, frequency $=10 \mathrm{~Hz}$, run to 10 million cycles. The load cell capacity was $15 \mathrm{kN}$. Second, a static test was conducted using a largerload-capacity servohydraulic axial testing machine (Instron 8502; Instron Corp.) under static conditions of ramp loading at $0.1 \mathrm{~mm} / \mathrm{s}$ crosshead displacement speed, until fracture of the head when the applied load was recorded. The load cell capacity was $50 \mathrm{kN}$. Again, three tests were run on each of the size 40 and 58 implants.

\subsubsection{Unsupported head strength test}

The most severe loading of the shell of the resurfacing head is in a crush loading scenario without

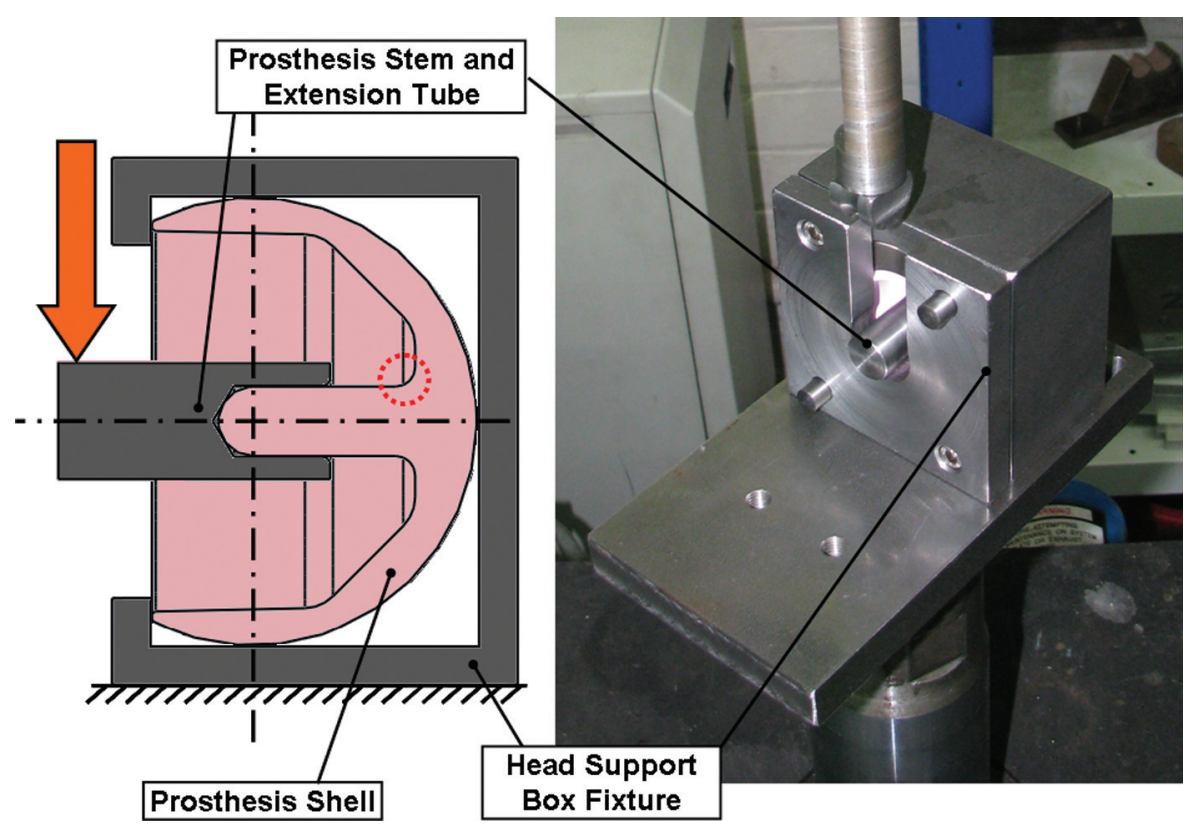

Fig. 2 Schematic drawing (left) and photograph (right) of the setup for the stem strength test. On the diagram, load is indicated by the arrow and the stressed stem root region is shown by the dashed circle 


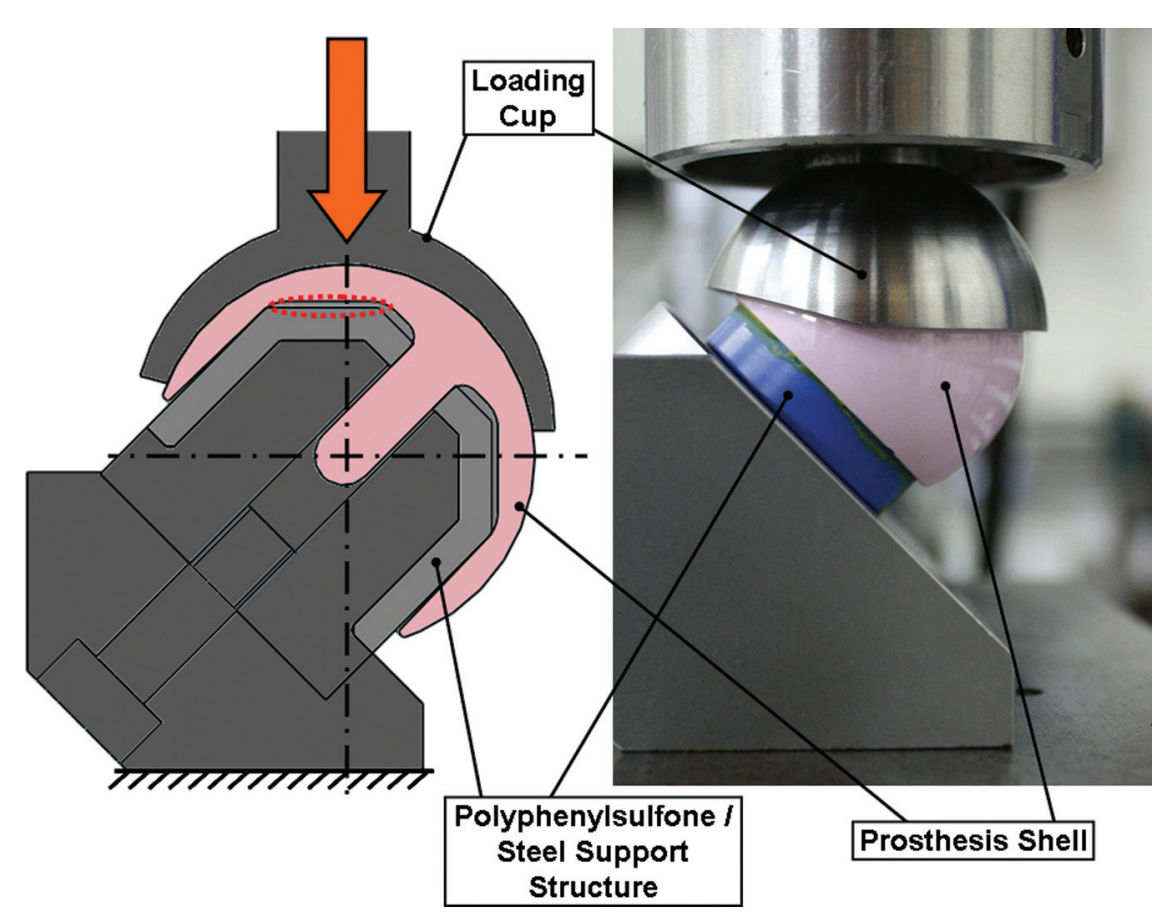

Fig. 3 Schematic drawing (left) and photograph (right) of the setup for the implanted head strength test. On the diagram, load is indicated by the arrow and the stressed implant wall region is ringed by the dashed line

internal support (Fig. 4). Although this is not a physiological load, it allows comparison with data for the yield point of conventional metal resurfacing heads reported by the CDRH [20]. Three implants of the extreme sizes 40 and 58 were placed on a polyethylene support with their stems horizontal, loaded by a metal acetabular cup. The test was carried out on the Instron 8502 test machine described in section 2.3.2, under static conditions of ramp loading, at $0.1 \mathrm{~mm} / \mathrm{s}$ crosshead displacement speed, until fracture of the head when the load was recorded. The load cell capacity was $50 \mathrm{kN}$.

To ensure the strength of the resurfacing head was not reduced by implantation, blocks of closed-cell polyurethane foam $\left(0.64 \mathrm{~g} / \mathrm{cm}^{3} \quad(40 \mathrm{pcf})\right.$ Sawbone; Sawbone AG, Malmö, Sweden) were machined into the shape of the prepared femoral head using the appropriate surgical reamers, and implantation of the prosthesis was performed using Palacos Low Viscosity PMMA bone cement (Heraeus Kulzer GmbH, Hanau, Germany) and ten blows with a $1 \mathrm{~kg}$ surgical hammer. The prostheses were then tested mechanically under the same unsupported test conditions (Fig. 4), until fracture of the head. Again, three implants of each of the 40 and 58 extreme sizes were tested.

\subsubsection{Prosthesis-cement fixation test}

This test verified the strength of the prosthesiscement interface using a modified version of BS725113 [31] (for THR prostheses), which tests the torsional resistance of modular femoral heads. In the present tests, the prosthesis was implanted on a dense, $0.64 \mathrm{~g} / \mathrm{cm}^{3}$ Sawbone polyurethane foam replica femoral head with Palacos Low Viscosity PMMA bone cement. After implantation, the bearing surface of the head was bonded into a metal fixture with Araldite Rapid epoxy adhesive (Bostik Ltd, Leicester, UK). The fixture had a square key feature allowing connection to a digital torque wrench (Fig. 5). The structure was loaded with a static $1 \mathrm{kN}$ axial force, and torque was applied with the wrench until failure [31]. Again, three implants of each of the 40 and 58 extreme sizes were tested, using the Dartec 9610 test machine with a $15 \mathrm{kN}$ load cell. In this case, the peak load was recorded as the failure point.

\section{RESULTS}

Table 2 contains the results of the FEA and physical tests, and a calculated minimum safety factor for each.

\subsection{FEA}

The results of the FE model (Fig. 6) indicate three main stress concentrations, located:

(a) at the stem root;

(b) under the bearing contact patch on the chamfer face;

(c) in the prosthesis wall, near the rim. 


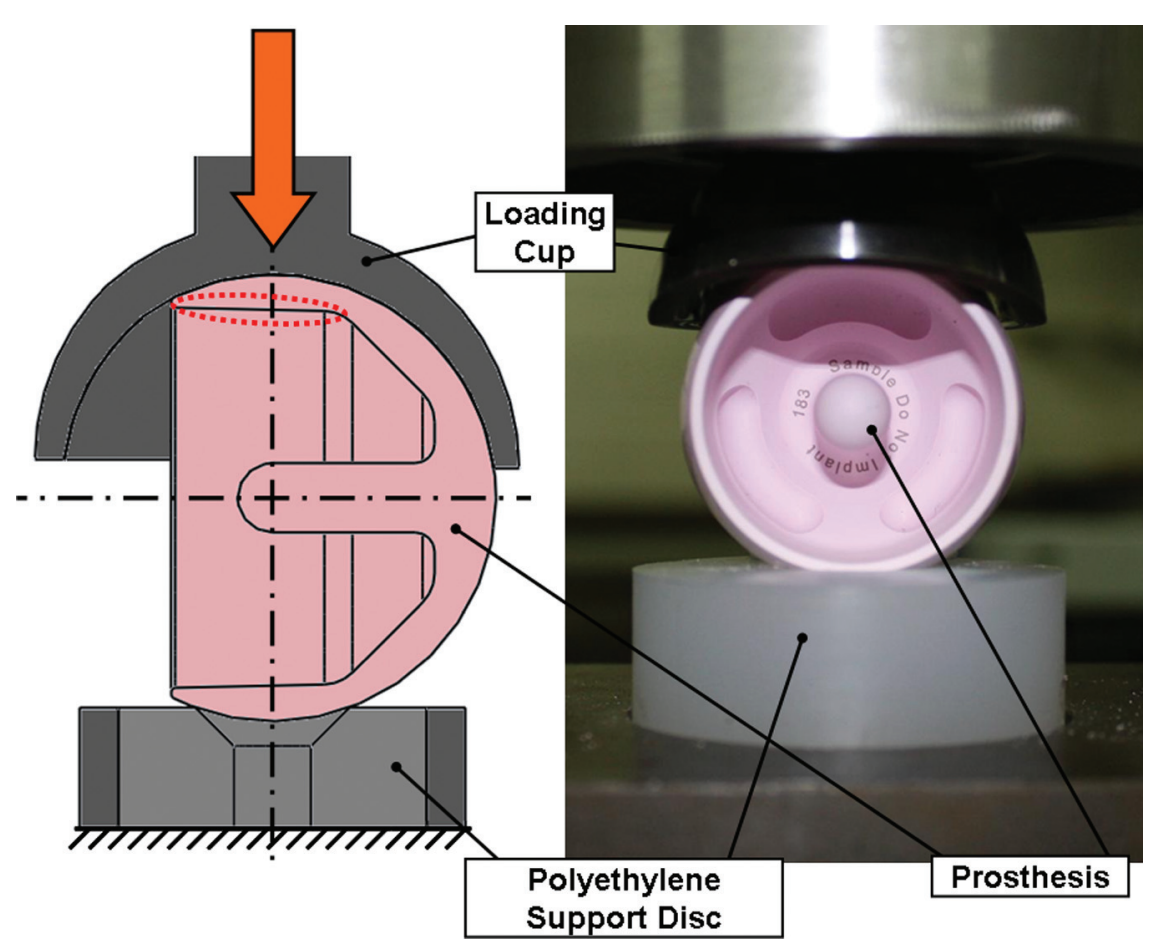

Fig. 4 Schematic drawing (left) and photograph (right) of the setup for the unsupported head strength test. On the diagram, load is indicated by the arrow and the stressed shell wall and rim region is ringed by the dashed line

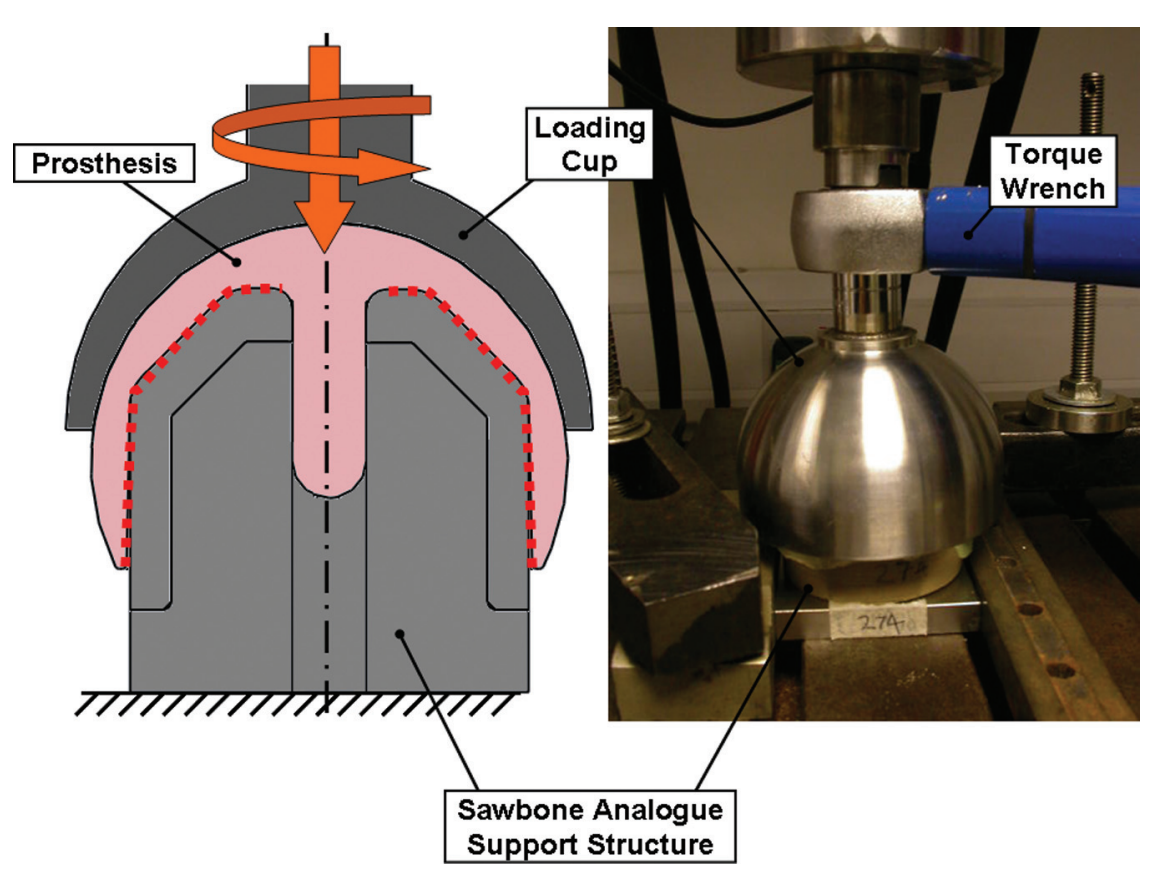

Fig. 5 Schematic drawing (left) and photograph (right) of the setup for the prosthesis-cement fixation strength test. On the diagram, axial load and torque are indicated by arrows and the stressed prosthesis-cement bond is shown by the dashed line

With valgus orientation, the stem root stress concentration dominated, but as orientation became neutral and varus, the stress concentrations on the chamfer face and at the rim became significant. The peak predicted tensile stress in the prosthesis was $212 \mathrm{MPa}$ under $8 \mathrm{kN}$ in varus orientation. A factor of 
Table 2 Summary of the test results and calculated factors of safety

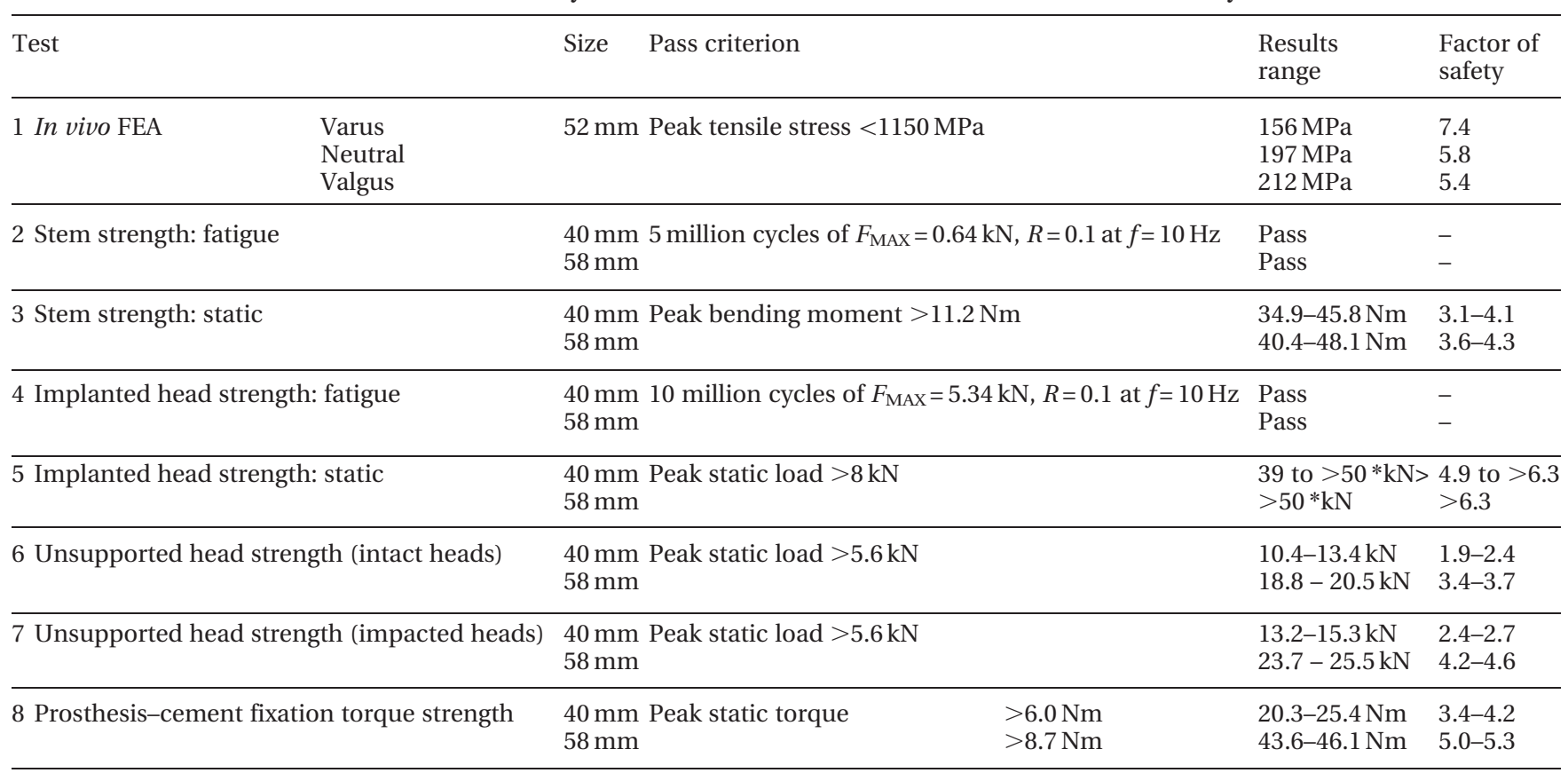

*Denotes test exceeded limit of test machine load cell, $50 \mathrm{kN}$.

safety was calculated as 5.4, taking the material's $1150 \mathrm{MPa}$ fracture strength [21] divided by the peak first principal (tensile) stress.

\subsection{Mechanical tests}

\subsubsection{Stem strength test}

All of the stems survived fatigue loading (Fig. 2). The minimum equivalent load on the stem tip at fracture was $2.37 \mathrm{kN}$ and $1.58 \mathrm{kN}$ for the size 40 and 58 heads, respectively. These results were used to compute the bending moment at the stem root (Table 2), of minimum $34.9 \mathrm{Nm}$ and $40.4 \mathrm{Nm}$ for the size 40 and 58 heads, respectively. The peak stem root stress predicted by the FEA was $156 \mathrm{MPa}$, when the prosthesis was in $10^{\circ}$ valgus orientation (Fig. 6). Using beam theory for a cantilever (solid circular cross-section; $9 \mathrm{~mm}$ diameter), this corresponds to a peak bending moment of $11.2 \mathrm{Nm}$. A factor of safety was calculated as 3.1 for this test, taking the experimental fracture moment divided by the peak in vivo cantilever moment.

\subsubsection{Implanted head strength test}

All of the heads survived inclined implanted fatigue loading (Fig. 3). In the implanted strength tests to failure, two of the size 40 heads failed at 39 and $50 \mathrm{kN}$ respectively, and the third did not fail at the limit of the load cell $(50 \mathrm{kN})$. None of the $58 \mathrm{~mm}$ heads failed at the limit of the load cell (Table 2).
Factors of safety were calculated as $>4.9$ and 6.3 for the size 40 and 58 heads respectively, taking the experimental fracture load divided by a typical maximum load experienced in vivo, measured in the region of $8 \mathrm{kN}[\mathbf{2 8}]$.

\subsubsection{Unsupported head strength test}

The minimum fracture load of the ceramic resurfacing head under the unsupported crush load (Fig. 4) was $10.4 \mathrm{kN}$ and $18.8 \mathrm{kN}$ for the size 40 and 58 heads, respectively (Table 2). Factors of safety were calculated as 1.9 and 3.4 for the size 40 and 58 heads, respectively, taking the experimental fracture load divided by the yield load of the BHR prosthesis, reported to be $5.6 \mathrm{kN}[\mathbf{2 0}]$. The strength of the ceramic resurfacing heads was not adversely affected by cementing and impaction onto polyurethane foam material. Indeed, the load at failure was increased slightly (minimum $13.2 \mathrm{kN}$ and $23.7 \mathrm{kN}$ for sizes 40 and 58, respectively; Table 2) because the analogue bone stub provided some support to the prosthesis.

\subsubsection{Prosthesis-cement fixation test}

For the fixation torsion tests (Fig. 5), the minimum fixation torque at failure was $20.3 \mathrm{Nm}$ and $43.6 \mathrm{Nm}$ for the size 40 and 58 heads, respectively (Table 2). An extreme limit of frictional torque experienced in vivo, $T_{\mathrm{e}}$, can be calculated as the product of the joint contact force $(5 \mathrm{kN}[\mathbf{2 8}])$, the friction factor value for 


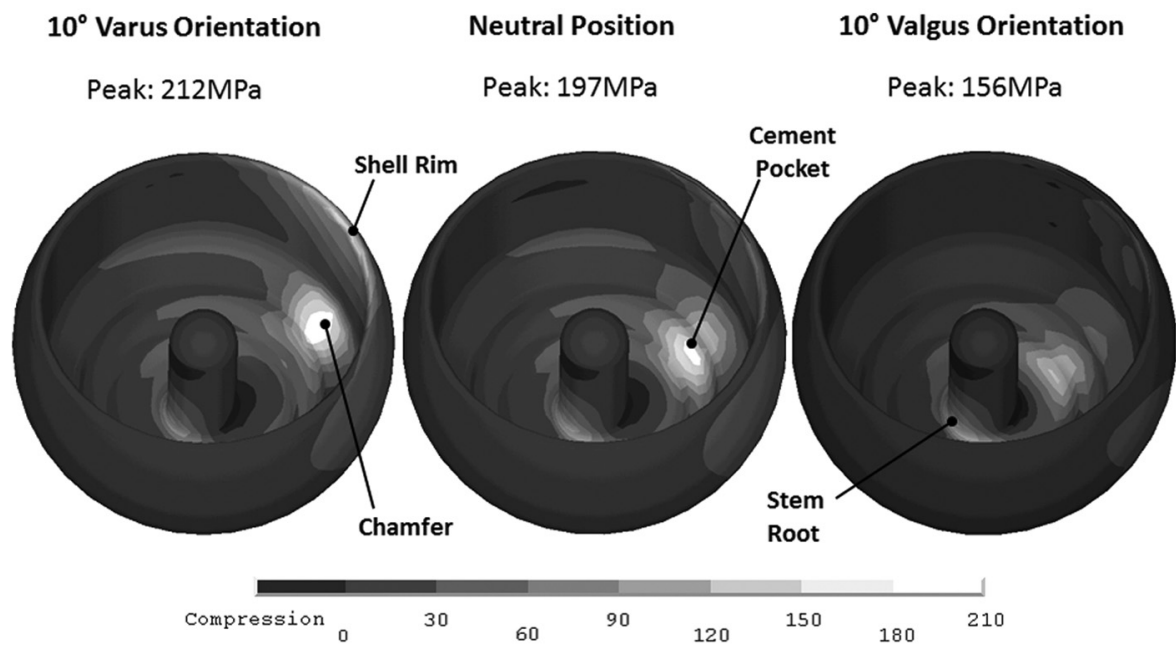

Fig. 6 FEA-predicted tensile stress (units: MPa) in the ceramic resurfacing head under $8 \mathrm{kN}$ in vivo stumbling load. Main stress concentrations shown on the chamfer under the contact patch, at the prosthesis shell rim, and at the stem root

a ceramic-on-ceramic or ceramic-on-metal bearing in a THR $(0.06[\mathbf{3 2}, \mathbf{3 3}])$, and the bearing radius. Thus, $T_{\mathrm{e}}$ was calculated as $6.0 \mathrm{Nm}$ and $8.7 \mathrm{Nm}$ for the size 40 and 58 heads, respectively. Factors of safety were calculated as 3.4 and 5.0 for the size 40 and 58 heads, respectively, taking the peak experimental torque divided by $T_{\mathrm{e}}$.

\section{DISCUSSION}

Metal-on-metal resurfacing has demonstrated high survivorship levels in demanding patients, but there remains a concern regarding the performance of these devices in patients with small hips, particularly females [3]. Elevated metal ion levels may be associated with these prostheses above the levels seen in small-diameter metal-on-metal THRs during the bedding-in period [34]. There is, therefore, an opportunity for a ceramic femoral resurfacing head that can provide all of the bone-conserving advantages of resurfacing without the potential limitations of metal ions. Although there has been some past clinical experience with ceramic resurfacing heads for which there were no recorded instances of ceramic fracture [8-12], fracture is the main concern with any new ceramic prosthesis and mechanical verification is vital. In the present study, a series of computational and mechanical tests was performed to investigate whether contemporary transformation toughened ceramic composites are suitable for use in hip resurfacing devices.

The present analyses and tests were limited to the mechanical fracture strength of the prosthesis and its interface with the cement mantle. Previous research has predicted reduced remodelling stimulus and femoral neck fracture risk for the proposed short-stemmed prosthesis geometry [25, 35, 36], so the behaviour of the supporting bone was not considered in these tests. Contemporary ceramic-onceramic bearings in THR also demonstrate excellent in vivo performance with regard to reduced osteolysis [19]. Therefore, the bearing was not considered a major risk in the prosthesis design. Verification was required for the use of the ceramic material in the prosthesis head, and its fixation to the femoral head with PMMA bone cement. The focus of the present work, therefore, was analysis of the strength of the prosthesis design and its fixation to the cement mantle.

The mechanical behaviour of the ceramic resurfacing head prosthesis was investigated with structural FEA, representing a stumbling scenario with valgus, neutral, and varus prosthesis orientation. A minimum safety factor of 5.4 was predicted between the peak tensile stress in the prosthesis and the strength of the BIOLOX Delta material, under extreme stumbling loads (Fig. 6). Validation of FEA results may always be questioned; so to allay these concerns, extensive verification and corroboration exercises were conducted on the current study's FE methodology, reported previously [24]. Ultimately, the high safety factor in terms of implant stress under stumbling loads indicates that the prosthesis would be sufficiently strong to avoid fracture and suggests that the prosthesis would be stronger than the femoral neck. With reported femoral neck fracture loads in the range of $3-16 \mathrm{kN}$ [37-39], the prosthesis strength would be expected to exceed that of the supporting bone. 
The nature of in vitro testing is that a test is never perfectly representative of the in vivo situation, and always represents a generalization or simplification of clinical conditions. To give confidence in the present methods and results, the tests were designed to be as representative of in vivo mechanical scenarios as possible or to represent a worse than actual case. In the test programme design, the results of the FEA confirmed the selection of mechanical tests, in terms of the stress concentrations resulting from in vivo loading.

With regard to the stem strength test (Fig. 2), loading the prosthesis stem as a cantilever is far more extreme than would occur in the body, where the stem is loaded along its length and where load is shared with the prosthesis shell. The stem was subjected to the same fatigue loading applied during verification tests of the established BHR prosthesis [20], despite the fact that the shorter stem would generate a considerably smaller bending moment. All stems survived 5 million cycles of fatigue loading. In metal-on-metal resurfacing devices in current clinical use, stem fractures have been reported only very rarely $[\mathbf{2 3}, \mathbf{4 0}]$. This could probably occur only in cases of advanced femoral head resorption or prosthesis misalignment, leading to load transfer by the stem alone. With the short stem in the present ceramic resurfacing head design, load transfer would always be shared more evenly between the stem and shell. This, in addition to a comparison of the minimum static bending fracture moment of $34.9 \mathrm{Nm}$ with the $11.2 \mathrm{Nm}$ bending moment calculated for an extreme $8 \mathrm{kN}$ stumbling load and varus orientation, gives confidence in the safety of the metaphyseal stem.

With regard to the impaction tests and inclined loading (Fig. 3), the analogue femoral heads used were stiffer than cancellous bone and made from either polyphenylsulfone or closed-cell polyurethane foam. By preventing any cement-bone interdigitation, there is no mechanism for bone-cement pressure relief. This represents theoretically a worst case in terms of implant stress. With regard to the unsupported head wall strength test (Fig. 4), a worse than realistic case of varus prosthesis positioning was used, with the stem axis horizontal, to produce very high stress in the prosthesis rim. Thus, although the minimum safety factor for the small head in these tests was the lowest in the programme at 1.9 , it was achieved for a very extreme loading scenario and poor prosthesis support, worse than the in vivo case. Because this was the least physiological load case, its pass criterion was defined in comparison to the reported yield load of the existing metal resurfacing head of $5.6 \mathrm{kN}$ [20], instead of a physiological load. Therefore, although metal-onmetal implants would not fail catastrophically, the result may represent an improvement in strength over existing designs. Finally, the minimum fracture loads sustained of $10.4 \mathrm{kN}$ (unsupported) and $39 \mathrm{kN}$ (inclined semi-physiological support) were higher than reported typical values of the overload strength of the femoral neck, which also indicates a very low risk of fracture of the prosthesis.

With regard to the prosthesis-cement interface test (Fig. 5), the torque was applied about the head axis. This allowed the structure to resist torque only through the shear strength of the interface, with no contribution from the geometric stability of the chamfered femoral head shape as would be offered in off-axis torsion. As there is no standard test method available for evaluating the integrity of this interface in a hip resurfacing system, the worst loading orientation relative to the prosthesis axis was used. It was found that the minimum torque strength of $20.3 \mathrm{Nm}$ exceeded a high-magnitude pass criterion.

Several limitations of this study should be acknowledged. Adequate performance in a mechanical test programme is a prerequisite for a clinical evaluation, but even with comprehensive testing, care should still be taken upon clinical release. This study presents tests to evaluate the mechanical strength of novel prostheses, but further investigation should be conducted prior to clinical use. As noted above, technological departures from existing, clinically successful implant systems should be verified. The fracture and adaptation responses of the bone supporting the prosthesis have been considered in past studies $[\mathbf{2 5}, \mathbf{3 5}, \mathbf{3 6}]$, but other areas requiring verification could include the tribological performance of the large-diameter bearing, and any necessary biocompatibility and cytotoxicity screening where new materials are employed or where different sized wear particles may be generated. Finally, it is difficult to define a maximum load magnitude or worst-case loading direction experienced in vivo under traumatic conditions, poor positioning, or inadequate support. Therefore, worst-case realistic scenarios were tested, and the resulting safety factors above the extreme pass criteria give some confidence in the prosthesis strength for excessive loading and cases of surgical error or inadequate supporting bone quality. Nevertheless, once clinical evaluations begin, the same level of care should be taken with respect to surgical training, operative technique, and patient selection.

In conclusion, ceramic resurfacing heads are conceivable following developments in the strength and 
reliability of ceramic materials through composite transformation toughening. A new design was presented and the validity of any departures from traditional metal designs was evaluated in a mechanical structural verification process, comprising FEA and physical tests. The development of the test programme represents an improvement in the state of the art where there is an absence of international test standards that refer to femoral resurfacing head prostheses. In the present study, the DeltaSurf ceramic resurfacing head prosthesis performed with high factors of safety compared with extreme in vivo loads in various loading scenarios. Similar verification tests should be designed and conducted for novel ceramic prosthesis designs in the future, leading the way to clinical evaluation.

\section{FUNDING}

This work was supported by the UK Government and Finsbury Development Ltd, under a Knowledge Transfer Partnership (KTP, number 6229) with the University of Southampton. At the time of preparing the manuscript, three authors (A C T, J R T J and K C W) were employees of Finsbury Development Ltd, and M B was a consultant to Finsbury Development Ltd.

\section{ACKNOWLEDGMENTS}

The authors would like to thank CeramTec AG for their involvement in the development process.

(c) Authors 2011

\section{REFERENCES}

1 Hedlundh, U., Ahnfelt, L., Hybbinette, C.-H., Wallinder, L., Weckstrom, J., and Fredin, H. Dislocations and the femoral head size in primary total hip arthroplasty. Clin. Orthop. Relat. Res., 1996, 333, 226-233.

2 McMinn, D., Treacy, R., Lyn, K., and Pynsent, P. Metal-on-metal surface replacement of the hip. Clin. Orthop. Relat. Res., 1996, 329S, S89-S98.

3 Australian Orthopaedic Association. National joint replacement registry annual report, Australian Orthopaedic Association, Adelaide, 2008.

4 McMinn, D. and Daniel, J. History and modern concepts in surface replacement. Proc. IMechE, Part H: J. Engineering in Medicine, 2006, 220, 239-251.

5 Pandit, H., Glyn-Jones, S., McLardy-Smith, P., Gundle, R., Whitwell, D., Gibbons, C. L. M., Ostlere, S., Athanasou, N., Gill, H. S., and Murray, D. W. Pseudotumours associated with metal-on-metal hip resurfacings. J. Bone Joint Surg. $B r ., 2008$, 90-B, 847-851.

6 Campbell, P., Shimmin, A., Walter, L., and Solomon, M. Metal sensitivity as a cause of groin pain in metal-on-metal hip resurfacing. J. Arthoplasty, 2008, 23, 1080-1085.

7 Boutin, P. Arthroplastie totale de le hanche par prostheses en aluminine fritte. Rev. Chir. Orthop., 1970, 58, 230-246.

8 Amstutz, H.C., Ebramzadeh, E., Sarkany, A., Le Duff, M., and Rude, R. Preservation of bone mineral density of the proximal femur following hemisurface arthroplasty. Orthopedics, 2004, 27, 1266-1271.

9 Wagner, H. Surface replacement arthroplasty of the hip. Clin. Orthop. Relat. Res., 1978, 134, 102130.

10 Freeman, M. A. R. and Brown, G. C. ICLH cemented double cup replacement. Arch. Orthop. Trauma Surg., 1978, 92, 191-198.

11 Furuya, K., Tsuchiya, M., and Kawachi, S. Socketcup arthroplasty. Clin. Orthop. Relat. Res., 1978, 134, 41-44.

12 Salzer, M., Knahr, K., Locke, H., and Stark, N. Cement-free bioceramic double-cup endoprosthesis of the hip-joint. Clin. Orthop. Relat. Res., 1978, 134, 80-86.

13 Capello, W. N., Ireland, P. H., Trammell, T. R., and Eicher, P. Conservative total hip arthroplasty. Clin. Orthop. Relat. Res., 1978, 134, 59-74.

14 Capello, W. N., Misamore, G. W., and Trancik, T. M. Conservative total hip arthroplasty. Orthop. Clin. North Am., 1982, 13, 833-842.

15 Hamadouche, M., Boutin, P., Daussange, J., Bolander, M. E., and Sedel, L. Alumina-on-alumina total hip arthroplasty: a minimum 18.5 year follow-up study. J. Bone Joint Surg. Am., 2002, 84-A, 69-77.

16 Amstutz, H. C., Le Duff, M. J., Campbell, P. A., and Dorey, F. J. The effects of technique changes on aseptic loosening of the femoral component in hip resurfacing. Results of 600 conserve plus with a 3 to 9 year follow-up. J. Arthoplasty, 2007, 22, 481489.

17 Steffen, R.T., Pandit, H. P., Palan, J., Beard, D. J., Gundle, R., McLardy-Smith, P., Murray, D. W., and Gill, H. S. The five-year results of the Birmingham hip resurfacing arthroplasty. J. Bone Joint Surg. Br., 2008, 90-B, 436-441.

18 Isaac, G. H., Brockett, C., Breckon, A., van der Jagt, D., Williams, S., Hardaker, C., Fisher, J., and Schepers, A. Ceramic-on-metal bearings in total hip replacement. J. Bone Joint Surg. Br., 2009, 91-B, 1134-1141.

19 Lusty, P. J., Tai, C. C., Sew-Hoy, R. P., Walter, W. L., Walter, W. K., and Zicat, B. A. Third-generation alumina-on-alumina ceramic bearings in cementless total hip arthroplasty. J. Bone Joint Surg. Am., 2007, 89, 2676-2683.

20 Center for Devices and Radiological Health, US Food and Drug Administration. Summary of safety and effectiveness data: Birmingham hip resurfacing (BHR) system, 2005, available from http:// www.accessdata.fda.gov/cdrh_docs/pdf4/ P040033b.pdf (accessed May 2007). 
21 Willmann, G. Improving bearing surfaces of artificial joints. Adv. Engng Mater., 2001, 3, 135-141.

22 Pollard, T. C. B., Baker, R. P., EastaughWaring, S. J., and Bannister, G. C. Treatment of the young active patient with osteoarthritis of the hip: a five- to seven-year comparison of hybrid total hip arthroplasty and metal-on-metal resurfacing. J. Bone Joint Surg. Br., 2006, 88-B, 592-600.

23 Ong, K. L., Kurtz, S. M., Manley, M. T., Rushton, N., Mohammed, N. A., and Field, R. E. Biomechanics of the Birmingham hip arthroplasty. J. Bone Joint Surg. Br., 2006, 88-B, 1110-1115.

24 Dickinson, A. S., Taylor, A. C., and Browne, M. Performance of the resurfaced hip. Part 1: The influence of prosthesis size and positioning on remodelling and fracture of the femoral neck. Proc. IMechE, Part H: J. Engineering in Medicine, 2010, 224, 427-440.

25 Dickinson, A. S., Taylor, A. C., and Browne, M. Performance of the resurfaced hip. Part 2: The influence of prosthesis stem design on remodelling and fracture of the femoral neck. Proc. IMechE, Part H: J. Engineering in Medicine, 2010, 224, 841851.

26 Taylor, M. Finite element analysis of the resurfaced femoral head. Proc. IMechE, Part H: J. Engineering in Medicine, 2006, 220, 289-297.

27 Morlock, M. M., Bishop, N., Ruther, W., Delling, G., and Hahn, M. Biomechanical, morphological and histological analysis of early failures in hip resurfacing arthroplasty. Proc. IMechE, Part H: J. Engineering in Medicine, 2006, 220, 333-344.

28 Bergmann, G., Graichen, F., and Rohlmann, A. Hip joint contact forces during stumbling. Langenbecks Arch. Surg., 2004, 389, 53-59.

29 MatWeb.com. Ensinger Radel ${ }^{\circledR}$ R-5500 polyphenylsulfone data sheet, 2010, available from http:// www.matweb.com/search/datasheettext.aspx?matg uid $=00049 f b 49 f 214 b 7 a a 3 b f 8672 a 5593 c 41$ (accessed January 2010).

30 ASTM International. ASTM F2068-09: Standard specification for femoral prostheses - metallic implants, 2009 (ASTM International, West Conshohocken, Pennsylvania).
31 British Standards Institution. BS7251-13:1995 Orthopaedic joint prostheses - Part 13: Method for determination of resistance to torque of head fixation of stemmed femoral components, 1995 (BSI, London).

32 Brockett, C., Williams, S., Jin, Z., Isaac, G., and Fisher, J. Friction of total hip replacements with different bearings and loading conditions. $J$. Biomed. Mater. Res., 2007, 81B, 508-515.

33 Scholes, S. C., Unsworth, A., and Goldsmith, A. A. J. A frictional study of total hip joint replacements. Phys. Med. Biol., 2000, 45, 3721-3735.

34 Venditolli, P.-A., Roy, A., Mottard, S., Girard, J., Lusignan, D., and Lavigne, M. Metal ion release from bearing wear and corrosion with $28 \mathrm{~mm}$ and large-diameter metal-on-metal bearing articulations. J. Bone Joint Surg. Br., 2010, 92-B, 12-19.

35 Dickinson, A. S., Browne, M., Jeffers, J. R. T., and Taylor, A. C. FE analysis of the effect of hip resurfacing stem design on femoral head and neck strains. Trans. ORS, 2008, 33, 1804.

36 Pal, B., Gupta, S., and New, A. M. Influence of the change in stem length on the load transfer and bone remodelling for a cemented resurfaced femur. J. Biomech., 2010, 43, 2908-2914.

37 Keyak, J. H., Rossi, S. A., Jones, K. A., and Skinner, H. B. Prediction of femoral fracture load using automated finite element modelling. J. Biomech., 1998, 31, 125-133.

38 Schileo, E., Taddei, F., Cristolfini, L., and Viceconti, M. Subject-specific finite element models implementing a maximum principal strain criterion are able to estimate failure risk and fracture location on human femurs tested in-vitro. J. Biomech., 2008, 41, 356-367.

39 Duchemin, L., Mitton, D., Jolivet, E., Bousson, V., Laredo, J. D., and Skalli, W. An anatomical subject-specific FE-model for hip fracture load prediction. Comput. Meth. Biomech. Biomed. Engng, 2008, 11, 105-111.

40 Gabriel, J.-L. and Trousdale, R. T. Stem fracture after hemiresurfacing for femoral head osteonecrosis. J. Arthoplasty, 2003, 18, 96-99. 